\title{
Sexual dimorphism and human enhancement
}

\author{
Paula Casal
}

Correspondence to

Professor Paula Casal, Department of Law, ICREA-

Univ. Pompeu Fabra, Trías

Fargas 25, Barcelona 08005,

Spain; paula.casal@upf.edu

Accepted 20 July 2012 Published Online First 8 September 2012

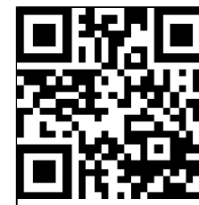

\section{SLinked}

- http://dx.doi.org/10.1136/ medethics-2012-100976

- http://dx.doi.org/10.1136/ medethics-2012-100978

- http://dx.doi.org/10.1136/ medethics-2012-101143

- http://dx.doi.org/10.1136/

medethics-2013-101802

To cite: Casal P. J Med

Ethics 2013:39:722-728.

\begin{abstract}
Robert Sparrow argues that because of women's longer life expectancy philosophers who advocate the genetic modification of human beings to enhance welfare rather than merely supply therapy are committed to favouring the selection of only female embryos, an implication he deems sufficiently implausible to discredit their position. If Sparrow's argument succeeds, then philosophers who advocate biomedical moral enhancement also seem vulnerable to a similar charge because of men's greater propensity for various forms of harmful wrongdoing. This paper argues there are various flaws in Sparrow's argument that render it unsuccessful. The paper also examines whether dimorphism reduction is a more desirable outcome than male elimination, thereby further illustrating the difficulties besetting the distinction between therapy and enhancement.
\end{abstract}

\section{INTRODUCTION}

In several recent papers Robert Sparrow alleges that those who, like John Harris and Julian Savulescu, advocate biomedical welfare enhancement are committed to selecting only female embryos because women live longer than men. ${ }^{1-3}$ As the next section explains, one could construct a stronger case for female selection when the project is not merely welfare but moral enhancement through drugs or gene selection. Having fleshed out this new possibility, which Sparrow leaves unexplored, the paper explains why male elimination does not follow from premises requiring welfare or moral enhancement, noting some non sequiturs in Sparrow's attempted reductio ad absurdum. It then explains the difference between the gradual disappearance of males and the gradual disappearance of dimorphic traits, like male aggression and reduced longevity, which are not inherent to maleness but side effects of our polygamous past. The last section employs dimorphism reduction to illustrate further difficulties with the therapy/enhancement distinction. The paper identifies those difficulties without advocating either welfare or moral enhancement; nor does it defend any particular permissible means that individuals or states may employ to achieve worthwhile goals. Instead, it focuses, like Sparrow, on what outcomes are desirable and what ambitions are appropriate for us to have.

\section{WELFARE AND MORAL ENHANCEMENT Welfare enhancement}

Sparrow argues we may aim to create children without pathological abnormalities but not children that are "better than well' ${ }^{1}$ (p. 4). He points to a relevant moral difference between suffering from something that is bad in absolute terms and places us below an adequate threshold, and merely failing to have the best possible prospects ${ }^{1}$ (p. 8, 10). He argues against aiming to benefit somebody independently of what would be 'natural' for that individual to have, and denies any reason to go beyond creating children who are 'normal' or 'good

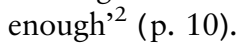

To be sure, normal intelligence and pregnancy's normal duration are averages, and so if individuals with below-average intelligence or premature deliveries cease to be born, normality will change and humans will be enhanced. Moreover, some medical conditions may be so common, for example, in old age or developing countries, that it is normal to exhibit them. Sparrow must therefore appeal to a 'suitably idealised account of proper species functioning, ${ }^{3}$ (p. 1) which may not differ from some enhancers' ideal and which Sparrow does not provide, failing even to specify if 'normality' is unrelated to statistical frequency or related but irreducible to it because it is dependent upon statistical and non-statistical considerations.

Sparrow grants 'the distinction between therapy and enhancement is extremely difficult to describe and defend and the argument that the distinction has no normative significance is even more compelling. ${ }^{2}$ (sic p. 117) But he urges us to retain this elusive distinction to avoid concluding that only girls should be born. Sparrow's argument for this provocative conclusion is that female longevity and capacity to bear children outweigh their lesser (eg, weight-lifting) abilities, ${ }^{2}$ (p. 130ff) and that other male advantages should be disregarded because they derive from injustice. He concludes that we must either reject enhancement or endorse the claim that humanity should be female. He rejects enhancement on the grounds that men have their own normality.

\section{Moral enhancement}

One might reject female selection on welfare grounds but still welcome it on moral enhancement grounds. After all, the welfare-based case for female selection is rather weak as neither men nor women can produce children alone and virtually all men prefer being able to have them without undergoing menstruation, pregnancy, childbirth, menopause and the risk of unwanted or abnormal pregnancies or miscarriages. These welfarediminishing costs, moreover, may outweigh additional years of old age. Moral enhancement also provides a stronger case because averting atrocity is far more urgent than extending human longevity. Utopian novels depicting female-only societies like Mizora, New Amazonia or Herland do not express longevity concerns but the hope for a world without war, violence, sexual abuse, animal cruelty and oppressive inequalities. Moral enhancement advocates, like Ingmar Persson and Julian 
Savulescu, also stress its special urgency, as the mismatch between our sophisticated technology and our primitive moral psychology makes catastrophe increasingly likely. Given those risks, they consider remaining natural less important than becoming more humane and moral (ie, more altruistic and just). ${ }^{4}$ (p. 107-8, 121, 125ff) As I write, the newsreader describes how in a place as civilised as Oslo, a man shot down dozens of teenagers in a youth camp because he found them too tolerant of other religions. Experts remarked how predictably the killer was male. Drawing on such observations, one might attempt to build a moral-enhancement case for female selection. To understand that case's appeal it is worth considering some evolutionary explanations of several characteristic male and female traits.

\section{SEXUAL DIMORPHISM AND MORAL ENHANCEMENT}

Different species vary greatly in their propensities to infanticide, femicide, homicide, genocide, rape and sexual harassment, as well as in their propensity to empathy, altruism, adoption, elderly care, resource sharing, cooperation and peacemaking. Two factors have special importance in explaining these tendencies: parental investment and polygamy.

\section{Parental investment}

Like other hominids, elephants and some cetaceans, humans belong to a group of unusually intelligent mammals capable of mirror self-recognition. These mammalian persons with longterm emotional memory and enormous imitative, linguistic, tool-using and problem-solving abilities can adopt the perspective of others, and respond to their distinct needs. For reasons I explain elsewhere, creatures with such features lie at one end of the $R / K$ spectrum of reproductive strategies, having very few offspring, and investing enormously in each, with great patience, empathy and altruism.

\section{Polygamy}

If the best human features derive from us being 'extreme $\mathrm{Ks}$ ' like some other mammals, the worst features derive from us being polygamous (one male mates with several females) like most mammals.

Polygamy results in the selection of the males who have what it takes to kill or defeat the largest number of other males. They may thus develop an excessive size for the food available, costly weapons and ornaments useless for anything other than competing with each other, ${ }^{6}$ (p. 115) and, of course, violent propensities. Gorilla silverbacks, for example, live in peaceful association with a group of females protecting their offspringa behaviour which may explain why silverback Jambo protected the boy who fell in the Jersey zoo enclosure in 2007. ${ }^{\mathrm{i}}$ Since one male monopolises several females, however, frustrated single males eventually team up and challenge the harem-keeper. And since each offspring requires the undivided attention of its mother for many years, the single males may never reproduce if they wait until all the silverback's offspring are self-sufficient. So, they have to kill his offspring and then persuade their mothers that all they can now do now is start over, mating with whoever can afford them the greatest protection: the very killer of their offspring. Combining $K$ strategies and polygamy then has tragic consequences even in what is otherwise a peaceful,

ihttp://www.youtube.com/watch?v=ihUGT7MdDB4\&feature =fvwrel (accessed June 2012). vegetarian, non-territorial society, free, for example, from the war and femicide of the chimpanzees.

In polygamous species, while male reproductive success depends on access to females, female success depends on access to food. $\alpha$ Males have access to more females, and $\alpha$ females to more resources, with males focusing more than females on sex and power, and females on offspring and nutrition. ${ }^{5}$ Depending on whether the task is to attack or to provide baby-care, it may pay to be patient or aggressive, prudent or daring, compassionate or brutal, with specialisation hampering role-reversal. This takes us to one last consequence of polygamy. A $K$ strategy is a species trait and so any of the endearing features that plausibly derive from it could, in principle, be equally visible in both sexes. Polygamy, however, drives males away from parenthood and towards competition over the control of females, who provide the parenting work. Orangutans, for example, the living hominid that most resembles our common great ape ancestor, nest so high in the canopy that any parental distraction could result in the offspring suffering a fatal fall. Yet, relatively small, single mothers do all the parenting work, lactating for 7 years, and transmitting orangutan culture to their offspring for a decade or more. Maternal care in hominids is not only essential for protection and survival in infancy and early adolescence but also to secure the offspring's normal mental and physical development and the cultural transmission required for long-term survival. Female nurturing propensities are unsurprising because they are absolutely necessary. ${ }^{7}$

\section{Oxytocin and empathy}

When huge maternal efforts are needed, as in orangutans and humans, the most caring and self-denying mothers achieve greater reproductive success, with females becoming more caring and self-denying over time. To ensure mothers perform all the required tasks with patience and perseverance even when stressed or ill, evolution has selected them to feel an intense love for their infants. Because of its intensity, the caring impulse spreads to anything that resembles their offspring, making all creatures with disproportionally large heads, hesitant steps and incompetent vocalisations seem adorable. The caring impulse extends to any creature that stumbles calling for its mother, and then to any vulnerable and needy individual. Interspecies altruism in males is less common but has been observed, and is more easily explicable, in species where males perform-like humans and gorillas-some parenting work.

Nature activates the mothering impulse through oxytocin, which triggers labour and then causes mothers exhausted by the birthing effort to respond lovingly to the irritating calls of their newborns, providing them with milk, with breastfeeding producing more oxytocin, contractions and pain. Oxytocin increases trust and empathy and facilitates the interpretation of bodylanguage to read the baby's mind, adopt its perspective and respond to its needs.

\section{Side effects of female selective pressures}

The female bonobo Kuni, for example, who stretched the wings of a stunned starling, carried it to the top of the tallest tree, and cared for it all day until it flew, demonstrated an ability to respond to needs she never had. ${ }^{8}$ (p. 2) ${ }^{4}$ (p. 109) These actions sometimes come at great cost, as when female chimp Washoe risked her life to rescue a drowning youngster she hardly knew, ${ }^{9}$ (p. 29) when female elephants save drowning infant rhinos despite repeated rhino charges, and when female cetaceans engage in altruistic interspecies protection against sharks. Interspecies altruism is also more often observed in human 
females, where animal protectors are predominantly female while bullfighters and other animal torturers are generally male. The same applies to the fostering of orphans, the feeding of mothers and grandmothers who have become too old or sick to feed themselves, and to other practices like comforting the bereaved. Among mammalian persons, peace-keeping and caregiving are predominantly female. We see this in neonates, with female newborns responding more than male newborns to the distressed calls of other babies and to the human face ${ }^{10}$ (p. 41, 43). We see it in childhood, with female chimps rocking sticks to sleep while contemporary males play aggressively. We even see it in entire species, in the male-dominated chimpanzee society, with homicide, femicide, genocide, infanticide and generally high levels of aggression, and the less dimorphic, femaledominated bonobo society, where other primates are not killed or terrorised and not a single homicide has been reported. Controlled experiments also show that spraying oxytocin increased generosity in ultimatum games, ${ }^{11}$ while administering testosterone caused people to make meaner offers, and increased their readiness to punish those who did not deliver what they wanted. ${ }^{12}$ There is, then, no shortage of biological data to build a case for female selection on moral enhancement grounds. Consider now psychological data.

\section{Testosterone and crime}

In Zero Degrees of Empathy, Simon Baron-Cohen analyses atrocities-like the Nazi amputation and re-attachment of hands in reverse just to see what would happen-and defines evil as 'the absence of empathy'. He notes that non-empathetic individuals, whether in the Asperger-autism spectrum or among psychopaths, are predominantly male, ${ }^{13}$ (p. 55$)^{4}$ (p. 111). The former's condition, which he associates with an 'extreme male brain', is linked to low empathy, trust, ability to read the minds and body language of others and to take their perspective. Since it is also associated with compulsive rule-following, however, it may cause strict adherence to moral principles, as in Karan Johar's moving film My Name is Khan. Louan Brizendine describes the emergence of the male brain as follows:

\begin{abstract}
until eight weeks old, every fetal brain looks female-female is nature's default gender setting. A huge testosterone surge beginning in the eighth week will turn this unisex brain male by killing off some cells in the communication centers and growing more cells in the sex and aggression centres ${ }^{10}$ (p. 36).
\end{abstract}

As a result,

the testosterone-formed boy brain simply does not look for social connections in the same way a girl brain does. In fact...autism spectrum disorders and Asperger's syndrome are eight times more common in boys...[T] he typical male brain... gets flooded with testosterone during development and somehow becomes more easily socially handicapped. Extra testosterone...may be killing off some of the brain's circuits for emotional and social sensitivity. ${ }^{10}$ (p. 47)

Unfortunately, the Khan-types do not balance out the impact of the serial killers, torturers, rapists, domestic violence perpetrators, and child molesters, who also are predominantly male.

Consider, for example, the following chart provided by Richard Wilkinson and Kate Pickett in a book which attributes a sweeping range of social ills to economic inequality rather than testosterone (figure 1). ${ }^{14}$ (p. 132)

According to this chart, women are so unlikely to murder that they are virtually equally unlikely to do so at age 4,14 or 40. In contrast, there is a shocking coincidence between homicide in males and the surge of testosterone in adolescence. The chart makes sense when we learn that the very same hormone causing men to be hairy, bald, strong and thick-skinned also makes them prone to aggression, risk-taking, sexual preoccupation and insensitivity to others' feelings.

This is a worrying combination but one may respond to such data by stressing the importance of individual life histories. For example, leaving genetic propensities $\operatorname{aside}^{13}$ (p. 89-95) it appears that many sociopaths lacked adequate maternal love (earlier cited as essential for normal development), and/or suffered physical or sexual abuse themselves. This is certainly the most common life-history for female criminals. According to the US Department of Justice 1993-97 data, males committed $98 \%$ of sexual offences, $93 \%$ of robberies, and $89 \%$ of aggravated assaults. ${ }^{15}$ Of the tiny minority of female inmates, $60 \%$ had undergone sexual abuse, and $40 \%$ were perceived by the victim to be under the influence of drugs or alcohol. ${ }^{15}$ Baron-Cohen's typical non-empathic female patients also lacked maternal love and/or were raped or abused. ${ }^{13}$ (p. $35 \mathrm{ff}$ ) So crime can be traced to testosterone either directly, as in the chart, or indirectly because being sexually abused can make victims, women included, capable of serious crimes.

\section{Side effects of male selective pressures}

If sexual abuse diminished, then other crimes could also diminish. But can sexual violence vanish without men doing likewise?

The answer depends partly on the explanation of sexual violence. Some authors consider rape an adaptation to transmit one's genes. ${ }^{16}$ (esp. p. 165) If so, impeding rapists' reproduction (through prison or optional drug treatment) could both deter them and weed out this trait from humanity. ${ }^{16}$ (p. 153) Other authors, however, ${ }^{17}$ deny sexual violence exists to transmit one's genes but consider it a side-effect of other more general male traits, like persistent sexual desire, aggression, strength and low risk-aversion.

Evidence supporting the latter more depressing conclusion includes the fact rapists do not always target fertile females. Male elephants, for example, target infants or rhinos, ${ }^{\text {ii }}$ male dolphins rape even turtles, and humans also rape males, and sometimes kill their fertile victims, eliminating any chance of conception. This suggests that just as intense love for our offspring can make us care for creatures quite unrelated to us, intense sexual desires can also extend to all sorts of targets. As we know, these may include individuals that are uninterested, terrified or dead, members of other species or subspecies (in our case, farm animals, Neanderthals ${ }^{18} \ldots$ ) and even the very same offspring that inspire maternal self-denial.

If so, it is less likely that sexual violence will disappear without men (or dimorphism, as the Sexual dimorphism section explains) disappearing. Are enhancers therefore committed to female selection? The next section questions the inference to an affirmative answer regarding welfare enhancement and then moral enhancement.

\section{HUMAN ENHANCEMENT AND SEX SELECTION When enhancement doctrines vary}

Enhancers may deny any commitment to female selection by insisting that the type of enhancement they support does not favour it. For example, some enhancers may advocate enhancing

iihttp://www.youtube.com/watch?v=rEGVH4IQ2nA (accessed June 2012). http://www.nytimes.com/2006/10/08/magazine/08elephant.html (accessed June 2012). 
Figure 1 Homicide by age and sex of perpetrator. England and Wales compared with Chicago.

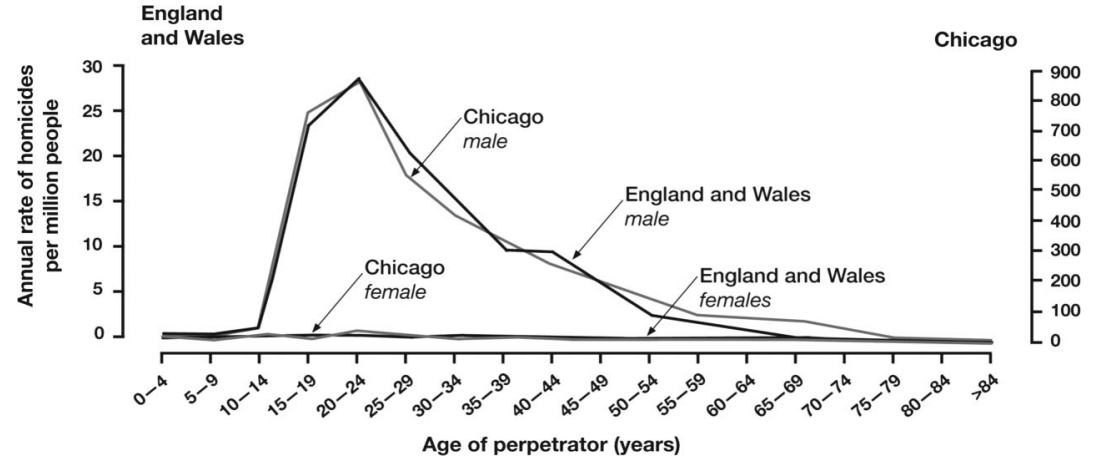

specific human beings but eschew enhancing humanity by replacing some individuals by others through embryo or sperm selection. Other enhancers may support only those improvements which are major and certain, and then deny female selection qualifies on either count, arguing for example, that male and female lives and respective contributions to society are just incommensurable. And even if there were some differences, many enhancers also deny that every sub-optimality justifies intervention even if they nevertheless also insist that once a condition, such as impaired vision, merits intervention then intervention should aim at providing the patient with the best vision affordable rather than the sufficiently good vision that could have justified non-intervention. On this view, absent severe differences at birth between men and women, intervention would simply be uncalled for. Some doctrines supporting enhancement, then, can resist Sparrow's inference at the very outset.

Even enhancement doctrines favouring the provision for each child of any trait that would improve his life however slightly could still resist Sparrow by plausibly ruling out interventions with significant negative externalities, such as upsetting sex ratios or risking human extinction. Moral enhancers, furthermore, may not support interventions that are objectionably discriminatory in discarding on statistical grounds individuals who have not, and perhaps will never, have harmed anyone. Given their concern with harm-reduction, moreover, it would be natural for them also to oppose interventions with harmful externalities.

\section{When negative externalities are present}

Sparrow attempts to exclude this last response by distinguishing individual parents from social policy-makers, and claiming that neither agent has adequate reasons to refrain from interventions with negative externalities.

Regarding individuals, Sparrow's reply is that 'any particular couple's reproductive decision will have only an infinitesimal impact on society's gender ratios'. ${ }^{3}$ (p. 2) This claim is also available to individuals in China, India and Nepal who abort female fetuses. Each contributes only slightly to the scarcity associated with Asia's high rates of girl kidnapping and trafficking and other sex-ratio related problems well-described in Maalouf's novel, The First Century after Beatrice. In fact, given the high costs of having a girl for many Asians, their aborting female fetuses is easier to justify than aborting male embryos on longevity grounds. Sparrow's reply fails because in the absence of important costs for the contributor, it can still be wrong to make even very small contributions towards disaster. ${ }^{4}$ (p. 66-85) There is even a philosophical literature exploring whether-like its Kantian, contractualist and ruleconsequentialist rivals-act-consequentialism possesses sufficient resources to condemn making insignificant contributions towards disaster, or should instead be rejected. ${ }^{19-21}$ So, Sparrow's response to the individual case is unpersuasive because it assumes it is of no moral relevance if we each contribute a little to disasters like climate change-an unattractive and widely contested premise for which he provides no defence.

Regarding social policy, Sparrow claims that if enhancers like Harris $^{22}$ are concerned with extinction, this discredits their view by placing it 'firmly in a tradition of eugenic thought that argues that we should settle the question of 'what sort of people should there be' by reference to what would maximise social welfare'. ${ }^{3}$

A concern with extinction, however, is a concern with a minimum threshold, and not evidence of a plan to 'maximise' anything. It is also odd to describe doing nothing as an example of 'eugenic social engineering' ${ }^{3}$ (p. 1, 2, 4). Aware of this oddity, Sparrow focuses on an imaginary practice that remains objectionable whether it involves acts or omissions, namely, bringing into existence individuals with lives barely worth living just to feel (comparatively) lucky ourselves. ${ }^{3}$ This practicerather uncharacteristic of old eugenics-may be criticised for reasons inapplicable to the present case.

First, the avoidable creation of lives barely worth living is itself abhorrent regardless of its motivation. Second, the motivation is morally repugnant and too trivial to bear on such a momentous decision. Harris's case, by contrast, involves allowing the birth of men, who just have a slightly shorter life expectancy than women, and the avoidance of disaster for men as well. Those differences are not trivial. We would be required to license a treatment able to restore to normality all lives barely worth living, regardless of whether it will trim the welfare of those who love comparing themselves favourably to others. By contrast, we would not be required to license a treatment that could slightly increase male life-expectancy if its side effects included human extinction. Thus Sparrow's response to the social policy case is also unsuccessful. Equating concerns with extinction and eugenics is utterly far-fetched. As I shall now explain, the comparison is also contestable should it be employed against Sparrow's own view.

\section{When the same problems emerge with therapy}

Suppose that a treatment, initially believed to increase male lifeexpectancy directly, is then discovered to cure a medical condition, the removal of which causes an increase in male lifeexpectancy as a by-product. Suppose that since the treatment can now be justified on therapy grounds, Sparrow supports licensing it. He then discovers the treatment's side effects include extinction. Now, if Sparrow licences the treatment, his 
position is implausible. But if he declines in order to avoid extinction, he cannot criticise Harris for doing likewise.

The emergence of similar problems within a therapy perspective is bad news for Sparrow, as the point of his reductio was to establish therapy as the way to avoid these problems. In pursuing this strategy, however, Sparrow overlooks the possibility that therapy itself may face comparable challenges.

For example, Sparrow selectively considers some of the effects of testosterone, such as greater strength and diminished longevity, but not other effects described earlier. If we include them all, the possibility arises that the concern to avoid pathologies, which animates therapy, also supports either the elimination of males or of sexual dimorphism (a disjunction the next section explains) as a means to minimise murder, rape and atrocity, which are bad for everybody, including the perpetrators.

This problem remains if we understand therapy as the removal of what is harmful, or bad in absolute rather than comparative terms, or what causes suffering rather than mere suboptimality. Thus, therapy faces comparable problems to enhancement. In fact, despite its name, and its refusal to grant 'the natural or normal' privileged normative importance, moral enhancement could also be seen as a form of therapy insofar as it aims merely at reducing wrongdoing rather than at producing supererogatory agents.

One may also distinguish versions of therapy and enhancement which are more or less aware of the existence of two sexes and conclude that such awareness is a feature of any wellinformed theory and not something necessarily linked to therapy or enhancement. For example, feminists working in the philosophy and history of science have noted a tendency within the therapy tradition to employ a conception of species normality built around men, which made women appear inferior, deviant and in need of therapy. It would be unfair, however, to reject the therapy perspective because it included genderunaware variants which identified, or measured, pathologies by employing an androcentric conception of normality. And it is similarly unfair to reject enhancement because of an imaginary variant that is so gender-unaware, and perhaps also species-unaware, it does not realise a womb will not enhance a male, any more than fur will enhance a whale.

\section{When there are many counterfactuals}

A third problem with Sparrow's reductio concerns counterfactuals. Since it would not make sense to describe as 'welfare enhancement' the creation of individuals who spend their slightly longer lives bemoaning the lack of companions whose existence we are deliberately impeding, Sparrow assumes women reproduce alone and do not miss male companionship nor anything else men provide, and all have technology that renders male strength unnecessary for any task. ${ }^{1}$ (p. 5). His imaginary world is also free from dowry, patrilocality and violence-three major reasons why people abort or kill baby-girls - and women are never sexually molested, battered, trafficked, discriminated, undervalued or underpaid, and are neither subordinated housewives nor stressed double-shifters.

One may invoke these counterfactuals to affirm that even in these unreal scenarios we still lack reasons to select out males. Sparrow, however, assumes these counterfactual scenarios and then insists we are discussing 'a choice with dramatic implications for real-world reproductive decision making, ${ }^{1}$ (p. 10) so that if the options are the status quo or destroying all male embryos, enhancers are committed to the latter. This is a non sequitur for the various reasons stated earlier as well as because of the counterfactuals employed.
The same problem applies to Sparrow's other concluding statement that unless we adopt his position, 'there is no way to explain why there is no good reason to make the next generation 'better than men' by making sure they are all female'2 (p. 138). The example is too far removed from reality to have implications for 'real-world decisions' let alone for those decisions concerning 'the next generation'.

The case for female-selecting moral enhancement is arguably different: while selecting female embryos on welfare enhancement grounds requires imagining women are not the victims of oppression, sexual predation or violence, selecting women on moral enhancement grounds merely requires noting they are more often the victims than the perpetrators.

The idea that fewer males results in less sexual abuse, atrocity and inhumanity is the constant theme in the literary tradition mentioned earlier. Crime disappears not only in the all-female, parthenogenetic societies of Mizora and Herland but also in those of New Amazonia and Sultana's Dream where men are the controlled minority. Perhaps merely having fewer men could reduce crime.

Enhancers, however, can still resist Sparrow's conclusion for any of the abovementioned reasons. In addition, we should point out that the crime-reduction hypothesis relies on the questionable assumption that women in a female world will remain as they are in a men-dominated world. Furthermore, we should note that male scarcity will not only deprive humanity of men's numerous positive contributions but may also bring back polygamy, which correlates with male violence and reduced longevity, gender and social inequality, and even despotism and invasion. ${ }^{23}$ A recipe for envy, jealousy and exploitation, polygamy is also probably capable of prompting increased wrongdoing in both sexes. We would then be paying a very high price quite absurdly, because, as I shall now argue, what enhancers should see as desirable is precisely the end of polygamy and the gradual disappearance of some of the dimorphic traits it causes rather than the gradual disappearance of men themselves.

\section{SEXUAL DIMORPHISM}

Sparrow argues we should celebrate sexual dimorphism rather than permit or prefer only the birth of females ${ }^{1}$ (p. 10) ${ }^{2}$ (p. 136-8). This is a false dichotomy, however, because we may welcome the gradual disappearance of certain dimorphic traits, like taller bodies, or greater aggression, without preferring the gradual disappearance of males.

Whatever our position on welfare and moral enhancement or therapy, discussing male elimination is misguided because the problems with longevity or aggression are linked to dimorphism rather than to maleness as such: in species where males and females co-parent roughly equally, dimorphism tends to be limited and unproblematic. Equally small, peaceful and longlived parents take turns and derive many advantages from cooperation. In other species, like the pipefish, where males do the parenting work, it is large, ornamented, territorially aggressive females that compete for the male labour. For the females of some species release the eggs and run off, dumping on the father the parenting work, and acquiring the traits that in other species often belong to the males.

Sparrow says that dimorphism is good, ${ }^{1}$ (p. 136ff) but dimorphism tends to be the proportional result of inequality in parenting. ${ }^{24}$ In mammalian species where the intensity of sexual competition among males has historically exceeded that among females, compared to females, males are generally: (i) larger and/or better armed and ornamented; (ii) more aggressive; (iii) more drawn to competitive, aggressive play; (iv) more likely to 
engage in escalating violence, leading to injury or death; (v) more prone to high risk behaviour, particularly when pursuing females; (vi) more eager to mate; (vii) less discriminating about mates; (viii) more likely to die in accidents, combat or from disease; (ix) less long-lived through physiological malfunction; and $(\mathrm{x})$ are conceived and born in larger numbers, roughly balancing their dying prematurely in larger numbers too. ${ }^{16}$ (p. 37)

In some species, while mothers and grandmothers remain useful and thus alive for decades after menopause, ${ }^{25}$ the best that large, resource-guzzling, aggressive males can do for their offspring is just what they do: to go away or to die, and often both, as nature does not invest in the longevity of creatures likely to succumb to accidental or violent death anyway ${ }^{6}$ (p. 115). Dimorphism can be accentuated by differential habitat exploitation because of the male propensity to kill or to monopolise the most convenient or nutritious resources. However, it is more often the outcome of males engaging, like feudal lords, in (sometimes lethal) competition among themselves to control females' eggs and devoted labour rather than engage in some of that labour themselves. It causes inequality not only among the sexes but throughout society and in humans it has also been found to be deeply connected to despotism and invasion. ${ }^{23}$ Genetic testing suggests despots and invaders impregnated astonishing numbers of women. For example, $8 \%$ of North Asians and $0.5 \%$ of humans appear to descend from Genghis Khan and his close male relatives. ${ }^{26}$ Moral enhancers thus have reasons to be wary of polygamy rather than maleness.

Polygamy causes sexual differences in all species. And in mammalian persons, with huge maternal investment, dimorphism is stark and there is fierce competition for females' scarce eggs and devoted labour. As explained in the Sexual dimorphism and moral enhancement section, the combination of polygamy and an enormous maternal investment is tragic because of the cognitive and emotional capacities that tend to accompany so large an investment, ${ }^{5}$ and because competition intensifies when the stakes are larger, and involve, for example, a decade of maternal labour. The result is the regrettable coexistence of very sophisticated and caring mammalian persons with brutal murders, rapes and infanticides, ${ }^{5}$ and the clash of dimorphic psychological adaptations such as indiscriminate sexual desire on one sex and determined protection of both infants and mate choice on the other ${ }^{16}$ (p. 39).

Fortunately, there may be light at the end of this tunnel, as there is some evidence of a gradual march towards dimorphism reduction among our hominid ancestors. We cannot, of course, be sure about our species' past or know its future but evidence from different fields yields a plausible story. The fossil remains of Aegyptopithecus, Australopithecus Afarensis, Australopithecus Africanus, Homo Erectus, Homo Habilis and Neanderthals show a marked reduction in dimorphism across time. ${ }^{27}$ (p. 453ff) There is also similar evidence from biology, such as that pertaining to the very dimorphic orangutan, the hominid that remained closest to our common great ape ancestor; and we have archaeological and ethnographic evidence indicating widespread polygamy in most primitive societies, ${ }^{25} 28$ as well as evidence of increased paternal empathy and involvement in childcare, and decreased violence over time. ${ }^{7}$ The emerging picture of our ancestors is that of individuals who were more polygamous, ${ }^{29}$ dimorphic and brutal than us, which is why we still exhibit all the abovementioned ten marks of polygamy. ${ }^{16}$ (p. 37)

Readers who do not recognise some of the features in themselves may be already 'evolved humans'. Today's most caring, and loyal males, however, still inhabit bodies designed to attack others because the past leaves its marks. But at least we seem to be on the right path to enhancement already, and it is worth discussing the possibility of accelerating this trend to complete the discussion of sexual dimorphism in the therapy/enhancement debate.

\section{REDUCING DIMORPHISM}

The media has recently reported the discovery of the 'monogamy gene RS3 334' or, more accurately, genetic variants of the vasopressin receptors in alleles of the gene AVPR $1 \mathrm{a} .{ }^{30}$ It is not difficult to imagine that many men and women would have some preference to procreate with carriers of the gene rather than with those with a greater propensity to abandonment and cheating. Suppose people undergo voluntary tests and advertise their vasopressin receptors like they advertise their STD-clear condition. Suppose too that the spread of these receptors strengthening pair-bonding and companionship reduces divorce rates, and divorce-associated child poverty. There is also a smaller incidence of suspicion-triggered anxiety and violence, sexually transmitted disease and sexual predation, helping us break the chain of abuse and crime described earlier.

The enhancers' response to this scenario would be clear: if these vasopressin receptors promote both welfare and moral enhancement, it is good that they become more common, regardless of how 'common' or 'normal' they were in the past.

Sparrow's position is harder to fathom, among other reasons because we do not know what a 'suitably idealised account of proper species functioning, ${ }^{3}$ involves. Sparrow may claim that welcoming, or contributing to, the spread of the receptors because of the welfare and moral gains they generate would be objectionable eugenics. Other therapy advocates may disagree, however, and defend the legitimacy of their being motivated not only by how a condition harms the patient but also by how it affects the patient's family, and even society at large.

A second thought-experiment further illustrates the difficulty in applying the therapy/enhancement distinction to the discussion of dimorphism. Given that not all human societies practiced polygamy to the same extent, and that some are less dimorphic than others, we can imagine finding some remote societies which vary considerably along these dimensions.

Compare, then, Equalia, an imaginary peaceful, social and gender egalitarian society, populated by equally sized and longlived co-parenting couples and Dimorphia with its more violent, non-parenting, harem-keepers towering over the females and dying before them. Most would find the former a more attractive future for humanity, and again, while the enhancer's response is clear, the therapy perspective is more obscure.

Given Equalian men's greater longevity and their deviation from the species norm for humans, Sparrow might consider Equalia a possible outcome of enhancement. Instead, he might think of the Equalians as cured of harmful polygamous tendencies and so judge the society an illustration of therapy. He might also argue that although species normality matters, subspecies normality matters too, and even this small ethnic group can have its own normality. Or perhaps, given that Sparrow emphasises species normality and celebrates current dimorphism, he might consider Equalia an example of decay. A final option would involve declaring Equalia none of the above, which suggests that the distinction between therapy and enhancement is non-exhaustive as well as unclear since some changes are instances of neither therapy nor enhancement.

Thus, by focusing on sexual dimorphism and more specifically, on typical features of polygamy like longevity and strength, Sparrow not only fails to overcome the problems surrounding 
the therapy/enhancement distinction, but actually provides us with an example of how quite muddled the application of these terms can be. A final thought-experiment can further illustrate this difficulty. Suppose that when researching dimorphism reduction in the human lineage, we discover a tribe called the Eve where women are almost as tall, fast and strong as men. As a result, men cannot easily rape and strangle with their bare hands women who are normally unable either to resist or outrun them. Moreover, as height and strength correlate with other advantages ranging from intimidating capacity to employment-income, the Eve are very gender egalitarian. Finally, the greater female size also makes pregnancy and childbirth easier and so almost all mothers and babies survive the process unharmed. Further research suggests the cause of all these marvels is an enormous female consumption of a spinachlike leaf in childhood.

Having thoroughly researched the case, and ensured there are no unwanted side effects, we perfect 'the Eve Diet', and also produce new pregnancy dietary supplements and baby formula, managing to outdo the Eve's results. We practically eliminate gender inequalities in height, strength and speed, with cultural changes following through. For example, Popeye no longer needs to defend Olive from Bluto because she now eats the greens herself. The combined effect of these changes does not yield a society as good as that of the smaller Equalians but still produces large welfare and moral gains.

Turning to evaluate the example, the enhancers' view is once again clear. They would deem it wrong, and misguidedly conservative, for Sparrow to keep his own daughter deliberately small and weak in order to maintain the 'normal' anatomical inferiority. By contrast, the implications of the therapy doctrine are much less clear.

The case involves developing an artificial treatment to create women who are not merely 'normal' or 'above a basic threshold' but superwomen in comparison to their female ancestors. Advocates of therapy may oppose researching the Eve treatment as an unjustified expense but not oppose licensing it once available. Or they may oppose licensing it, so not everybody feels under pressure to take it, but not researching it, because they do not oppose research as such. Further, they may allow only small doses, which fall far short of producing equality, but still lower the rates of rape or maternal death to an acceptable level. Or they may have still further reactions because Sparrow's doctrine is so ill-defined that we know he thinks it lacks one implication of enhancement but we know little more. And a critique of one version of enhancement should not be mistaken for a defence of therapy.

\section{CONCLUSION}

While the case for male elimination on welfare enhancement grounds is flimsy, if the logic behind it was sound, it would be possible to construct a stronger case for male elimination from moral enhancement premises. The reductio, however, involves questionable steps in either case. First, enhancement theories which do not advocate every conceivable instance of enhancement are not vulnerable to the reductio. Second, even radical enhancement theories do not lead to the counterintuitive conclusion because they do not recommend enhancements with harmful externalities. This proviso is a natural component of any moral theory based on beneficence, and it is unconvincing to dismiss it as old eugenics. Third, therapy cannot be the way to avoid the challenges facing enhancement because therapy itself confronts similar challenges. Fourth, Sparrow's case for male elimination on welfare enhancement grounds relies on too many counterfactuals to have practical significance for real world decisions. Finally, it is important not to conflate male elimination with the reduction of some polygamy-related dimorphic traits, which is far more likely than male elimination to lead to both welfare and moral enhancement.

If the opportunity arises, and permissible means exist, then we surely have good reasons to move closer to a society like Equalia, which lacks various regrettable features typically linked to polygamy, such as inequality, sexual violence and homicide. If the therapy doctrine cannot accommodate this conviction, the case of sexual dimorphism not only fails to establish that only the doctrine of therapy is defensible but actually renders the doctrine less plausible. As well as highlighting various difficulties with the therapy/enhancement distinction, the case of Equalia illustrates what an improved humanity might look like, showing how the welfare and moral enhancement of humanity could simultaneously be accomplished.

Acknowledgements For helpful comments, I thank Î́igo González, Ingmar Persson, Allen Buchannan and especially Andrew Williams.

Competing interests None.

Provenance and peer review Not commissioned; externally peer reviewed.

\section{REFERENCES}

1 Sparrow R. Should human beings have sex? AJOB 2010;10:3-12.

2 Sparrow R. Better than Men? Sex and the therapy/enhancement distinction. KIEJ 2010;20:115-44.

3 Sparrow R. Fear of a female planet: how John Harris came to endorse eugenic social engineering. J Med Ethics 2012;38:4-7.

4 Persson I, Savulescu J. Unfit for the future. Oxford: Oxford University Press, 2012

5 Casal P. Love not war. On the chemistry of good and evil. In: Gosseries A, Vanderborght Y, eds. Arguing about justice. Louvain: Louvain University Press, 2011:145-57.

6 Diamond J. The rise and fall of the third chimpanzee. London: Vintage, 2002.

7 Hrdy S. Mothers and others. Cambridge Mass: Harvard University Press, 2009.

8 De Waal FBM. Our inner ape. London: Granta Books, 2005.

9 Fouts R, Fouts D. Chimpanzee's use of sign language. In: Cavalieri P, Singer P, eds. The great ape project. New York: St. Martin's Press, 1993.

10 Brizendine L. The female brain. London: Batam Books, 2006.

11 Zak PJ, Stanton AA, Ahmadi S. Oxytocin increases generosity in humans. PLOS ONE 2007;2:e1128. doi:10.1371/journal.pone.0001128.

12 Zak PJ, Kurzban R, Ahmadi S, et al. Testosterone administration decreases generosity in the ultimatum game. PLOS ONE 2009;4:e8330. doi:10.1371/journal. pone. 0008330

13 Baron-Cohen S. Zero degrees of empathy. London: Penguin, 2011

14 Wilkinson R, Pickett K. The spirit level. London: Penguin, 2009.

15 U.S. Department of Justice, Women Offenders. Bureau of Justice Statistics Special Report 2000. http://www.bjs.gov/content/pub/pdf/wo.pdf (accessed 6/2011).

16 Thornill T, Palmer C. A natural history of rape. Cambridge: MIT Press, 2000.

17 De Waal FBM. Survival of the rapist. NYT, 2/4/2000.

18 Green RE, Krause J, Briggs AW, et al. A draft sequence of the neanderthal genome. Science 2010;328:710-22.

19 Glover J, Scott-Taggart M. It makes no difference whether or not i do it. Proc Aristotelian Soc, Supp Vol 1975;49:171-209.

20 Parfit D. Reasons and persons. Oxford: Oxford University Press, 1986.

21 Kagan S. Do i make a difference? Philos Public Aff 2011;39:105-41.

22 Harris J. Sparrows, hedgehogs and castrati. J Med Ethics 2011;37:262-66.doi:10. 1136/jme 2011;2011.043695.

23 Betzig L. Despotism and differential reproduction. New York: Aldine de Gruyter, 1986.

24 Trivers R. Parental investment and sexual selection. In: Campbell B, ed. Sexual selection and the descent of man, 1881-1971. Chicago: Aldine, 1972.

25 Clutton-Brock TH, Isvaran K. Sex differences in ageing in natural populations of vertebrates. Proc Biol Sci 2007;274:3097-104.

26 Zerjal T, Xue Y, Bertorelle $\mathrm{G}$, et al. The genetic legacy of the mongols. AJHG 2003; 72:717-21

27 Frayer DW, Wolpoff MH. Sexual dimorphism. Ann Rev Anthropol 1986;14:429-73.

28 Daly M, Wilson M. Sex, evolution and behaviour. North Scituate: Duxbury, 1983.

29 Wrangham R. Catching fire, London: Basic Books, 2010.

30 Walum $\mathrm{H}$, Westberg L, Henningsson $\mathrm{S}$, et al. Genetic variation in the vasopressin receptor 1a gene (AVPR1A) associates with pair-bonding behaviour in humans. PNAS 2008:105:14153-6. 